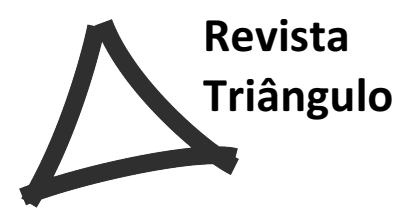

\title{
ATUAÇÃO, FORMAÇÃO E CONTEXTO ESCOLAR: TRAMAS DA/NA PRÁTICA PEDAGÓGICA DE PROFESSORES DE EDUCAÇÃO FÍSICA EM UMA ESCOLA TÉCNICA NO SUL DE MINAS GERAIS
}

\author{
ACTING, FORMATION AND SCHOOL CONTEXT: PLOTS IN EDUCATIONAL \\ PRACTICE OF PHYSICAL EDUCATION TEACHERS ON A TECHNICAL SCHOOL IN \\ THE SOUTH OF "MINAS GERAIS" STATE
}

Keila Miotto $^{1}$

\begin{abstract}
RESUMO
O trabalho discute a prática pedagógica dos professores de Educação Física de uma Escola Técnica e a possível relação com o contexto histórico da Escola e da própria área. A escola, localizada no sul de Minas Gerais, foi criada em 1918 no modelo das antigas escolas agrotécnicas. Na Educação Física, as modalidades esportivas e a preparação de equipes se fizeram tradicionais nesse contexto escolar, sendo que a disciplina e a competição eram parte da formação dos alunos-atletas. Frente às solicitações contemporâneas, o desafio posto aos professores é construir educação escolar que contemple, por um lado, o currículo escolar e, por outro, o interesse e necessidade de seus jovens alunos. Pesquisa de abordagem qualitativa, realizou-se entrevistas com os professores e pesquisa documental. Os resultados indicaram que mudanças na atuação dos docentes têm acontecido de forma gradativa a partir das situações cotidianas em que certezas deixam de responder às questões da prática.
\end{abstract}

Palavras chave: Educação Física. Práticas Pedagógicas. Formação Docente.

\begin{abstract}
The paper discusses the teaching practice of physical education teachers in a technical school and the possible relation to the historical context of the school and their own area. The school, located in the south of Minas Gerais, was created in 1918 on the model of the old agro-technical schools. In physical education, the sports and the preparation of teams became traditional in this school context, since the discipline and competition were part of the formation of the student-athletes. Faced with contemporary requests, the teachers imposed challenge is to build education that includes, on one side, the school curriculum and on the other, the interests and needs of their young students. As a qualitative research, interviews were conducted with teachers and documentary research. The results indicated that changes in theperformanceofteachershavehappenedgraduallyfromeverydaysituations in which certainties fail to respond to questions of practice.
\end{abstract}

Keywords: Physical Education. Pedagogical practices. Teacher Education Training.

\footnotetext{
${ }^{1}$ Instituto Federal de Educação, Ciência e Tecnologia do Sul de Minas Gerais- Campus Inconfidentes. E-mail: Keila.miotto@ifsuldeminas.edu.br
} 


\section{Introdução}

A pesquisa foi desenvolvida no contexto de uma Escola Técnica cuja origem é de 1918, localizada no sul de Minas Gerais, destinada à formação de profissionais para atuar no trabalho agrícola atendendo à demanda da região. Neste contexto, as histórias da Escola e da própria Educação Física foram construídas entrelaçadas. A Educação Física em sua origem, contribuía com a formação de mão de obra modelada e capacitada (LINO, 2007) e, na Escola em que a pesquisa foi desenvolvida, o esporte - meio de controle e disciplina - foi o conteúdo de maior significação da/na prática pedagógica dos professores. Porém, as solicitações contemporâneas colocam em discussão as reais finalidades e proposições da disciplina na escola.

$\mathrm{Na}$ referida Escola Técnica o desafio que atualmente tem sido colocado para os professores que lá atuam, muitos dos quais ex-alunos e/ou atletas da Escola, é, nas condições dadas, considerando-se o contexto histórico em que atuam, desenvolver prática pedagógica que considere a atual realidade e necessidade dos alunos, o que implica na ressignificação dos seus saberes.

A prática pedagógica é caracterizada por ações didático-pedagógicas que se desenvolvem na relação ensino-aprendizagem e na interação professor-aluno. São ações educativas promovidas pelos docentes, na interação com os alunos. Deve-se considerar também que as práticas pedagógicas se desenvolvem em contextos educacionais específicos formados por histórias que os constituem, o que também interfere nas ações docentes (FRANCO, 2012).

Um conceito importante para o entendimento da prática pedagógica é o habitus, conceito este que corrobora com a compreensão de que as ações docentes se relacionam aos contextos onde são desenvolvidas:

um sistema de disposições duráveis e transponíveis que, integrando todas as experiências passadas, funciona em cada momento como uma matriz de percepções, apreciações e ações e possibilita o cumprimento de tarefas infinitamente diferenciadas graças à transferência analógica de esquemas (BOURDIEU; PASSERON, 1982, p. 261)

Neste texto será apresentado um recorte da pesquisa, com foco nas entrevistas realizadas com os professores, cujas respostas serão analisadas entrelaçadas à história da Escola. O recorte temporal apresentado é o da criação dos Jogos Escolares na década de 60, 
uma tradicional competição que acontece internamente em cada unidade de ensino e entre as mesmas, em nível da região. O foco histórico nos Jogos Escolares tem como objetivo investigar sua relação com a construção das práticas pedagógicas dos professores de Educação Física.

\section{Práticas Pedagógicas, Contexto Escolar e Formação Docente - o referencial teórico da pesquisa}

A prática pedagógica se caracteriza como o conjunto de ações docentes produzidas tendo como relação às experiências que trazem consigo os professores, adquiridas ao longo da sua formação acadêmica, profissional, cultural e social. Considera-se também que as práticas pedagógicas se se definem na interação com os alunos e em relação ao contexto em que são produzidas (FRANCO, 2012).

$\mathrm{O}$ ensino acontece como atividade que dirige as trocas educativas e a intervenção sobre os grupos de escolares (GÓMEZ, 1998). Considerado como prática social, o autor ressalta que o ensino se constitui em diferentes formas em função das trocas que se realizam entre professor, professores, alunos e o contexto. Afirma a importância de se conhecer a vida na sala de aula para que o ensino se reverta em aprendizagem:

O ensino é uma atividade prática que se propõe dirigir as trocas educativas para orientar num sentido determinado as influências que se exercem sobre as novas gerações. Compreender a vida da sala de aula é um requisito necessário para evitar a arbitrariedade na intervenção. [...] A vida na sala de aula, dos indivíduos e dos grupos que nela se desenvolvem, tem muitas formas diferentes de ser e diversos modos de manifestação em virtude das trocas e interações que se produzem, tanto nas estruturas das tarefas acadêmicas como nos modos de relação social que se estabelecem. (GÓMEZ, 1998, p. 81).

Este autor considera o caráter de intervenção do ensino sobre a aprendizagem, o que precisa de reflexão em relação à reprodução que se estabelece (ou que pode se estabelecer) no interior dos contextos escolares.

$\mathrm{Na}$ busca por explicações sobre a relação entre a atuação do professor, a prática pedagógica e o contexto onde se desenvolvem, os estudos Bourdieu e Passeron dois autores se fizeram importante, na compreensão ás nossas dúvidas e inquietações. Os autores apresentam em suas obras o estudo das organizações sociais, com destaque para o poder que alguns grupos exercem sobre outros, bem como para a manutenção, pelas instituições entre as quais a 
escola, das desigualdades provocadas por essas relações de poder (BOURDIEU; PASSERON, 1982). Sobre a educação, se volta à reprodução, afirmando que a instituição escolar é uma das instâncias responsáveis pela manutenção dos privilégios sociais advindos da divisão em classes, ou seja, o desempenho escolar não está ligado apenas aos "dons individuais" dos alunos e sim, nessa perspectiva, à origem social de cada um, sendo que os que mais se adaptam ao poder social dominante e do sistema escolar mais se destacam e têm oportunidades na sociedade e no ambiente escolar (BOURDIEU, 1996). Ao mesmo tempo, o autor apresenta possibilidades de mudanças a partir da conscientização dos indivíduos sobre os mecanismos de poder que agem na esfera social e educacional.

Entre os conceitos apresentados pelo autor, destacamos o habitus (BOURDIEU; PASSERON, 1982), conceito que se fundamenta na teoria da prática social. O habitus, construído na família, escola e vivência profissional, se apresenta como a exteriorização das interiorizações do individuo (NOGUEIRA; NOGUEIRA, 2009, p. 23-24).

Tendo como referência este conceito podemos inferir que a prática docente - o modo como trabalha o professor - se relaciona às suas experiências, formação profissional e também ao contexto de atuação.

$\mathrm{Na}$ docência, ao assumirem o habitus os professores se veem bem sucedidos em suas práticas, tomando decisões e estratégias que são adequadas ao contexto escolar específico e, de forma mais ampla, ao social. Porém, os docentes, envolvidos na sua própria prática, desconhecem que o habitus é produto, e ao mesmo tempo é produtor, da ordem que o legitima:

\footnotetext{
A legitimação da ordem estabelecida pela Escola supõe o reconhecimento social da legitimidade da escola, reconhecimento que repousa por sua vez sobre o desconhecimento da delegação de autoridade que fundamenta objetivamente essa legitimidade ou, mais precisamente, sobre o desconhecimento das condições sociais de uma harmonia entre as estruturas e os habitus bastante perfeita para gerar o desconhecimento do habitus como produto reprodutor daquilo que o produz e o reconhecimento coorrelativo das estruturas da ordem assim reproduzida (BOURDIEU; PASSERON, 1982, p. 214-215).
}

A estrutura participa da formação do habitus dos sujeitos porque reproduz as relações hierarquizadas e impõe o arbitrário da cultura dominante, como sendo os costumes, as ações, os modos da classe dominante (BOURDIEU; PASSERON, 1982). A dominação da cultura se faz pelo não conhecimento dos indivíduos que se calam diante da imposição do habitus na reprodução da desigualdade, não respeitando diferenças sociais. Mudanças somente serão 
possíveis quando os agentes reconhecerem a ilegitimidade desse processo, questionando-o e possibilitando transformações. É de responsabilidade do sistema de ensino e de seus agentes se comprometerem na transformação social e no processo de produção e acesso ao conhecimento, questionando as formas de imposições da cultura dominante.

Cabe ao professor, nesse processo, refletir, individual e coletivamente, sobre seu papel como formador, concebendo possibilidades de ações, transformando e modificando a estrutura do campo escolar. Porém, para tal, precisa também tomar consciência dos processos de formação a que é arbitrariamente submetido e que, para além da formação profissional inicial (mas também a partir dela), participam da sua constituição profissional e do desenvolvimento de suas ações: manutenção da ordem estabelecida ou transformações? É nessa bipolaridade que atua o professor. Refletir sobre tal situação pode promover a reconstrução/construção de práticas docentes outras; a reflexão sobre a experiência pode caracterizar-se como formação.

Acerca do saber e do fazer dos docentes atravessados pela reflexão e a atuação profissional como síntese da própria formação docente, que o autor compreende como processo continuado (TARDIF, 2007). Compreendendo os saberes docentes como "saber plural, formado pelo amálgama, mais ou menos coerente, de saberes oriundos da formação profissional e de saberes disciplinares, curriculares e experienciais” (TARDIF, 2007, p. 36), o autor afirma que a experiência é mobilizadora dos saberes docentes que são ressignificados pela própria experiência. Refletir sobre a prática, possibilita a sua transformação e o seu aperfeiçoamento, porque é nesse exercício do cotidiano que acontecem "os medos, as angustias, os avanços e as conquistas" (SILVA, 2011, p, 345), podendo o professor colocar-se em diferentes situações, procurando atender as necessidades e possibilidades do ensino. Ainda para a autora, "as experiências vivenciadas no ambiente escolar são estruturas para a formação, atuação e a aprendizagem docente" (SILVA, 2011, p, 349). É nesse processo de aprendizagem e formação que o professor busca possibilidades de transformação e reconstrução da sua prática pedagógica.

\section{Metodologia}

A pesquisa desenvolvida, apresentada neste texto, teve como objetivo analisar a prática docente dos professores de Educação Física da Escola, investigando a possível relação dessas práticas com o contexto histórico da Educação Física na Escola, e da Própria Educação 
Física, focando, em especial, as atividades esportivas, as competições tradicionalmente realizadas na escola - os Jogos Escolares - e a preparação de equipes para essas competições na relação com as aulas de Educação Física, com a orientação curricular para a área e com o interesse e necessidade dos jovens alunos da Escola. A problematização que direcionou a investigação se estendeu a dois aspectos: que práticas de Educação Física escolar vêm construindo os professores de Escola Técnica em um contexto em que, nessa área, voltou-se a prática esportiva e ao treinamento? Como atuam os professores com alunos que, para além da motivação do próprio contexto educacional para a formação de atletas, resistem e/ou apresentam dificuldades nas práticas esportivas nas aulas de educação Física?

$\mathrm{Na}$ pesquisa, de abordagem qualitativa (LUDKE; ANDRÉ, 1986; BOGDAN; BIKLEN, 1994), se realizou entrevistas com os professores de Educação Física que atuam no Ensino Médio e a análise de documentos da instituição de ensino buscando-se por aspectos históricos que se referissem ao ensino da Educação Física naquele contexto. Frente à dificuldade de acesso a esses documentos, e/ou da sua inexistência, nessa fase da pesquisa, embora não estivesse previsto inicialmente, foram realizadas entrevistas também com exprofessores da Escola, que atuaram no período de 1975 a 2005.

\section{Trajetórias, experiências e os saberes dos professores de educação física e sua relação contexto histórico - Resultados e discussões}

Criada como Escola Agrotécnica, em 1918, na cidade de Inconfidentes - MG, a Escola Técnica em que a pesquisa foi desenvolvida, federalizada em 2008, é atualmente composta por seis unidades. Inicialmente, se constituiu da fusão de três antigas escolas agrotécnicas, localizadas nas cidades de Machado e Muzambinho, além da unidade de Inconfidentes, já mencionada. Posteriormente, foram criadas três novas unidades nas cidades de Passos, Poços de Caldas e Pouso Alegre, totalizando assim, o conjunto de seis unidades de ensino. Com a missão de promover a excelência na oferta da educação profissional e tecnológica oferece educação superior, básica (Ensino Médio) e profissional, com enfoque na educação profissional e tecnológica (ESCOLA, 2009).

A relação entre a Educação Física e a formação profissional é apresentada por vários autores, que destacam a importância da mão de obra fisicamente controlada (LINO, 2007), sendo a Educação Física Escolar responsável pela manutenção da saúde e a recuperação da força do trabalho dos alunos. Na Escola investigada essa relação se evidenciou por toda a 
história da instituição. Já na década de 60, a Educação Física na Escola voltou-se ao esporte, objetivando o desenvolvimento e treinamento de equipes em modalidades esportivas como vôlei, futebol, basquete e atletismo, visando à participação da Escola em diferentes tipos de competições, internas e externas. As aulas de Educação Física eram desenvolvidas em horários diferentes aos das outras disciplinas, os alunos mais "habilidosos", que se destacavam em modalidades esportivas, eram selecionados para representar a Escola, conforme relato do professor:

"A escola possuía mais de cinco categorias em treinamento de diferentes modalidades esportivas, mas a que mais se destacava era o futebol de campo e o diretor da escola era o treinador das equipes. Os alunos eram divididos por idade ou por habilidades. Alunos que jogavam bem estavam no time principal da escola e os outros, faziam de tudo para chegar ao time principal. Nós nem precisávamos cobrar deles, eles mesmos se esforçavam para atingir esse objetivo" [PEF2]2.

Com a prática de várias modalidades esportivas, e com a promoção de competições merecendo destaque, nesse período, a relação da Direção da Escola com a prática dos esportes também exercia incentivo aos professores para a prática do esporte. O treinamento acontecia de forma intensa e valorizada e alguns alunos tornaram-se atletas respeitados no cenário nacional, e outros escolheram a formação profissionais da área:

"Nós tínhamos treinamento esportivos todos os dias após o término das aulas. A escola se transformava em um campo de treinamentos em todas as modalidades, o campo de futebol, as quadras, a pista de atletismo, todas ocupadas, os treinos duravam das $16 \mathrm{hs}$ ate as 22hs, não tínhamos espaço para realizar mais nada, nos tínhamos atividades intensas todos os dia" [PEF7].

"Daqui da Escola, saíram jogadores profissionais, tínhamos equipes que participavam de campeonatos renomados no Brasil. O esporte na escola sempre teve destaque formando atletas de alto nivel" [PEF2].

A formação de equipes e o incentivo às competições iam ao encontro do momento histórico da Educação Física no país. As competições aconteciam anualmente. A competência, o êxito e a vitória eram estimulados entre alunos e professores:

"Nós tínhamos equipes fortes e muitos competitivas. Éramos chamados a participar de muitas competições na região, ainda disputávamos ligas de futebol de campo contra equipes profissionais e não fazíamos feio. Já nos jogos entres as Escolas,

\footnotetext{
${ }^{2}$ Os excertos das entrevistas e seus autores, serão identificados como $\mathrm{P}=$ Professor e EF= Educação Física, seguindo do número que corresponde à sequência em que a entrevista foi realizada.
} 
sempre tivemos o destaque nas competições individuais, como no Atletismo (arremesso, salto, corrida), Xadrez, Peteca e, nos esportes coletivos, sempre pegamos as primeiras colocações. Nós tínhamos uma potencia em se tratando de todos os esportes e éramos respeitados por isso na região, ou em qualquer lugar que fossemos disputar campeonatos" [PEF1].

$\mathrm{Na}$ década de 90, a Escola oferecia treinamentos de diferentes modalidades esportivas, sendo que o aluno que participasse desses treinamentos era dispensado pelos professores das aulas de Educação Física. Nesse período os professores de treinamento esportivo eram os mesmos das aulas de Educação Física e desenvolviam em suas práticas pedagógicas princípios de treinamentos, tais como atividades físicas e esportivas. $\mathrm{O}$ planejamento de aula visava o condicionamento do corpo, as modalidades esportivas e as atividades físicas.

Com o passar do tempo, mudanças foram acontecendo motivadas pelas alterações no quadro de docentes e também por novas orientações curriculares. Os Parâmetros Curriculares Nacionais (BRASIL, 2000), que são norte para as aulas de Educação Física no país, têm como princípio a cultura corporal, entre outros aspectos.

De acordo com os Parâmetros Curriculares Nacionais para a área (BRASIL, 2000), a Educação Física não deve se resumir apenas à prática de esporte, com novas solicitações e novos conhecimentos importantes na formação dos alunos, com a valorização das práticas corporais e da cultura corporal que se expressa com atividades diversificadas, jogos, ginásticas, lutas, dança e esporte, entre outras. Diante das novas solicitações da Educação Física, com diferentes proposições a respeito da sua importância e do seu objetivo como disciplina do currículo escolar, os professores procuram desenvolver conteúdos diversificados, conhecendo a realidade e a cultura que o aluno traz para o ambiente escolar:

"Eu fui professor de Fisiologia e estou tentando adaptar aqui no Ensino Médio. A Biologia e a Educação Física nunca deram tão certo! ’ [PEF3].

"Então trabalhos jogos, brincadeiras, esportes, as lutas e vários conteúdos da Educação Física, ginástica e também conhecimentos sobre o corpo" [PEF4].

"Trabalho com brincadeiras e jogos. Depende daquilo que os alunos têm interesse em fazer, e o esporte sempre prevalece. Hoje tem que tornar a aula de EF a mais agradável possível para que os alunos possam comparecer e participar, fazer com que o aluno goste da disciplina” [PEF7].

"Dentro da proposta para esse ano, estou trabalhando no $1^{\circ}$ ano a importância das atividades cooperativas, no $2^{\circ}$ ano, as praticas corporais alternativas, no $3^{\circ}$ ano, respostas do nosso corpo na atividade física: mitos e verdades (teoria e pratica) e no $4^{\circ}$ ano, a importância das atividades esportivas no processo de formação (jogos 
interclasse)" [PEF5].

Ressalta-se que atualmente a Educação Física vem se transformando em relação a seus objetivos de ensino e aprendizagem no ambiente escolar, podendo-se destacar ao fato de que, as demandas dos alunos, do ensino, do ambiente ou mesmo da cultura e sociedade vem apresentando uma "nova" concepção do papel da Educação Física na Escola. Diante do exposto podemos afirmar que os professores têm buscado a transformação e a ressignificação da sua prática pedagógica para oferecer aos alunos uma formação que não se resuma apenas à aprendizagem esportiva, mas que possa expandir conhecimentos para que estes tenham uma melhor qualidade de vida por meio da saúde (CAETANO; PIRES 2010).

Os professores, na entrevista realizada, também relataram acerca da sua trajetória e do contato com o esporte:

"Joguei vôlei durante a minha adolescência defendendo a equipe da cidade, disputava JIME (jogos competitivos)” [PEF3].

"Joguei algumas modalidades esportivas, eu fui arbitro de vôlei também, e isso teve influencia para a escolha da Educação Física como formação” [PEF5].

"Eu joguei futsal, o que influenciou minha escolha para a formação em Educação Física” [PEF6].

Destacamos que as experiências acontecem no contato direto com o que se faz, sendo este significativo para a aprendizagem, seja por meio do contato com a natureza, as pessoas ou objetivos culturais (GÓMEZ, 1998). As experiências são incorporadas sobre a forma de um saber e fazer no processo de formação (TARDIF, 2007). Sugere-se que a prática profissional futura é motivada por aprendizagens que, em muitos casos, ocorrem antes do curso de formação inicial.

Os Professores de Educação Física envolvidos nessa pesquisa, em sua maioria atletas, se apresentavam na sua trajetória escolar como alunos habilidosos que participavam de treinamentos e competições esportivas, sendo essa experiência marcante em sua formação, o que acabou, segundo seu próprio relato, se tornando uma orientação para a condução da prática profissional.

A experiência como atleta possibilitou aos professores a vivência em modalidades especificas e um desempenho que os destacavam nas aulas de Educação Física, compondo assim, uma bagagem cultural. Essa bagagem é constitutiva do professor e participa da 
construção de um habitus. No caso dos professores dessa Escola a experiência pessoal se complementa no contexto escolar, fortemente marcado pela prática esportiva. A bagagem que carrega o professor, os bens culturais, oriundos da família, sociedade e aqueles acessados através da escola, se constitui, e se complementa, nas experiências e vivências ao longo de sua formação (BOUDIEU; PASSERON, 1982). O habitus se constitui dessa bagagem na relação com o/s contexto/s, na interação com outros (pessoas e grupos).

Em se tratando da formação profissional dos professores, embora tenha sido historicamente marcada pela reprodução, fragmentação dos saberes profissionais e precarização da profissão, a ideia de formação como processo contínuo, que envolve diferentes vivencias e bagagens da/na trajetória de vida e profissão, deve ser considerada quando se pensa e se reflete sobre o professor. A ideia de formação refere-se a desenvolvimento pessoal, profissional e aos projetos da escola, indicando a necessidade de estabelecer relações entre a pessoa e o profissional quando se considera o ser professor (NÓVOA, 1995). Nessa perspectiva, a formação do professor se dá, portanto, num contexto de relações, o que consiste em concebê-la para além de uma dimensão técnica.

A pesquisa desenvolvida indicou que a prática pedagógica dos professores entrevistados se constitui, e se transforma, por ações que acontecem no ambiente escolar e que tem em sua base a história da instituição e de seus sujeitos. Os saberes docentes são ressignificados na prática cotidiana dos docentes, na e pela experiência (TARDIF, 2007).

\section{Considerações Finais}

Retomando as questões iniciais que originaram e nortearam o encaminhamento dessa pesquisa, a saber, como a prática pedagógica dos professores de Educação Física, em um contexto histórico voltado às atividades esportivas como único conteúdo trabalhado em aula, pode ser reconstruída e ressignificada, a pesquisa indicou que, embora a prática esportiva ainda esteja presente, e seja bastante valorizada, na realidade da Escola, frente à demanda contemporânea, os professores tem buscado dar outros sentidos a sua atuação. Nesse contexto, o "novo" aluno parece ser o responsável pelas mudanças gradativas que vem ocorrendo naquele ambiente. Entre reflexões e ressignificações, na organização de um novo caminho que atenda as necessidades do ensino e dos alunos, os professores têm buscado diferentes práticas que se reconstroem nas experiências do cotidiano escolar, nas escolhas e nos modos de ensinar cuja origem são seus saberes, trajetória de vida e formação. 
A Educação Física como um saber se caracteriza, se modifica e se transforma. O resgate histórico de sua construção indica para conteúdos voltados a disciplinarização, controle e desempenho do corpo e, mais recentemente, de forma mais ampla, a considerar a cultura individual e social dos alunos e demais sujeitos envolvidos.

No contexto da referida Escola, a Educação Física se fez fortemente ligada à promoção do esporte, à formação de equipes e à participação em competições, dando destaque a alunos habilidosos que eram valorizados pelo seu desempenho. Muitos outros alunos permaneceram alheios a essa história.

A escola, como um contexto social de formação, é decisiva para os sujeitos em sua inserção na sociedade; tem a função da transmissão dos saberes sistematizados e também estabelece regras de conduta. Nesse contexto, o habitus se caracteriza como o modo de ser, pensar e agir dos sujeitos e está relacionado às suas experiências culturais e sociais, e também com o campo social; o habitus se constitui entre a prática e a conjuntura social, entre a interioridade e a exterioridade.

As considerações a que se chegou indicam, porém, que esse processo de mudança tem se dado de forma contraditória em relação a alguns aspectos, por exemplo, quanto às estratégias usadas pelos professores para que os alunos participem das aulas, o que é associado às práticas avaliativas baseadas em punições. Mas, entendemos que as contradições fazem parte dos processos de mudança. A dinâmica do habitus na relação com o campo, na mediação dos agentes sociais, é sempre dialética uma vez que os sujeitos em sua vida, pessoal e profissional, estão "expostos objetivamente à historicidade de sua própria constituição" (SILVA, 2011, p. 337).

Os professores participantes da pesquisa, em sua maioria ex-alunos e atletas, quando assumiram as aulas deram continuidade ao trabalho presente nesta Escola, se tornando para além de professores de Educação Física, treinadores e formadores de equipes para a disputa dos Jogos Escolares entre as unidades de Ensino. Nesse sentido, a Escola e sua história foi preponderante na condução de ações voltadas à práticas tradicionalmente valorizadas naquele contexto. A práticas pedagógicas acontecem em contextos educacionais específicos, formados por história que os constituem e que, também, interferem nas ações dos professores (FRANCO, 2012). Porém, a prática pedagógica enquanto expressão dos saberes docentes tem relação com as experiências, vivencias e formação dos professores e também com o contexto de trabalho. O encontro com o aluno tem causado nos docentes dúvidas em relação ao ensino da área promovendo a busca por novas propostas, para que o conhecimento da disciplina 
efetivamente esteja voltado para a aprendizagem dos alunos, objetivando o conhecimento da cultura corporal, hábitos e vida saudável. Ainda que pequenas se observam mudanças que têm ocorrido no contexto da Escola em relação à prática da Educação Física.

\section{Referências}

BOGDAN, R.; BIKLEN, S. Investigação qualitativa em educação. Porto: Porto Editora, 1994.

BOURDIEU, P.; PASSERON, J. C. A reprodução: Elementos para uma teoria do sistema de ensino. Rio de Janeiro: Francisco Alves, 1982.

BOURDIEU, P. Razões práticas: sobre a teoria da ação. Campinas: Papirus, 1996.

BRASIL. MINISTÉRIO DA EDUCAÇÃO. Parâmetros Curriculares Nacionais: Ensino Médio. Brasília: MEC/SEF, $2000 . \quad$ Disponível em: http://portal.mec.gov.br/seb/arquivos/pdf/blegais.pdf Acesso em: setembro de 2015.

CAETANO, A.; PIRES, G. A relação teoria prática na Educação Física escolar: um constante desafio em questão. II Congresso Internacional de Formação Profissional em Educação Física. Santa Catarina: UFSC, 2010, p. 1521 - 1532.

FRANCO, M. A. S. Práticas pedagógicas nas múltiplas redes educativas. In: LIBANEO, J.C; ALVES, N. Temas de Pedagogia: diálogos entre didática e currículo. São Paulo: Cortez, 2012. p. $169-188$.

GÓMEZ, A. I. P. Ensino para a compreensão. In: SACRISTÁN, José Gimeno.; PÉREZ

GÓMEZ, I. A. Compreender e transformar o ensino. Porto Alegre: Artmed, 1998.p. 67-97.

LINO, C. F. Educação Física no Brasil: a história que não se conta. 13. ed. Campinas, SP: Papirus, 2007. 
LÜDKE, M.; ANDRÉ, M. E. A. Pesquisa em Educação: abordagem qualitativa. São Paulo: EPU, 1986.

NOGUEIRA, M. A.; NOGUEIRA, C. M. M. Bourdieu e a Educação. 3 ed. Belo Horizonte: Autêntica, 2009.

NÓVOA, A. Formação de professores e profissão docente. In: NÓVOA, A. (org.). Os professores e sua formação. Lisboa: Nova Enciclopédia, 1995.

SILVA, M. A. S. Habitus professoral e habitus estudantil: uma proposição acerca da formação de professores. Educação em Revista, Belo Horizonte, n.03, v. 27, p. 335-360, dez. 2011.

TARDIF, M.Saberes Docentes e Formação Profissional. 2. ed. Petrópolis: Vozes, 2007.

RECEBIDO EM: 03/03/2016

APROVADO PARA PUBLICAÇÃO EM: 29/06/2016 